\title{
A Versatile Method to Fabricate Highly In-Plane Aligned Conducting Polymer Films with Anisotropic Charge Transport and Thermoelectric Properties: The Key Role of Alkyl Side Chain Layers on the Doping Mechanism
}

\author{
Amer Hamidi-Sakr, Laure Biniek, Jean-Louis Bantignies, David Maurin, Laurent Herrmann, \\ Nicolas Leclerc, Patrick Lévêque, Vishnu Vijayakumar, Nicolas Zimmermann, \\ and Martin Brinkmann*
}

\begin{abstract}
A general method is proposed to produce oriented and highly crystalline conducting polymer layers. It combines the controlled orientation/crystallization of polymer films by high-temperature rubbing with a soft-doping method based on spin-coating a solution of dopants in an orthogonal solvent. Doping rubbed films of regioregular poly(3-alkylthiophene)s and poly(2,5-bis(3dodecylthiophen-2-yl)thieno[3,2-b]thiophene) with 2,3,5,6-tetrafluoro-7,7,8,8tetracyanoquinodimethane $\left(\mathrm{F}_{4} \mathrm{TCNQ}\right)$ yields highly oriented conducting polymer films that display polarized UV-visible-near-infrared (NIR) absorption, anisotropy in charge transport, and thermoelectric properties. Transmission electron microscopy and polarized UV-vis-NIR spectroscopy help understand and clarify the structure of the films and the doping mechanism. $\mathrm{F}_{4} \mathrm{TCNQ}^{-}$anions are incorporated into the layers of side chains and orient with their long molecular axis perpendicular to the polymer chains. The ordering of dopant molecules depends closely on the length and packing of the alkyl side chains. Increasing the dopant concentration results in a continuous variation of unit cell parameters of the doped phase. The high orientation results in anisotropic charge conductivity $(\sigma)$ and thermoelectric properties that are both enhanced in the direction of the polymer chains $\left(\sigma=22 \pm 5 \mathrm{~S} \mathrm{~cm}^{-1}\right.$ and $\left.S=60 \pm 2 \mu \mathrm{V} \mathrm{K}{ }^{-1}\right)$. The method of fabrication of such highly oriented conducting polymer films is versatile and is applicable to a large palette of semiconducting polymers.
\end{abstract}

\section{Introduction}

Conducting polymers were among the pioneering materials in the field of plastic electronics and have been the focus of intensive research efforts and studies in the early $1980 \mathrm{~s} .{ }^{[1,2]}$ Generally,

A. Hamidi-Sakr, Dr. L. Biniek, L. Herrmann, V. Vijayakumar,

Dr. M. Brinkmann

Université de Strasbourg

CNRS

ICS UPR22 F67000, Strasbourg, France

E-mail: martin.brinkmann@ics-cnrs.unistra.fr

Prof. J.-L. Bantignies, D. Maurin

Laboratoire Charles Coulomb

Université de Montpellier

F34095 Montpellier, France

DOI: $10.1002 / \mathrm{adfm} .201700173$ conducting polymers are obtained by redox or acid-type doping of highly conjugated polymers such as poly(diacetylene) or poly(aniline). ${ }^{[2]}$ At present, doped semiconducting polymers are present in the elaboration of numerous devices in the form of charge transporting or injecting layers. Poly(3,4-ethylenedioxythiophene):poly(styrenesulfonate) (PEDOT:PSS), for instance, is widely used in the fabrication of photovoltaic devices and more recently in thermoelectric (TE) devices. ${ }^{[3,4]}$ However, most conducting polymers are of poor structural quality as compared to semiconducting polymers such as poly(3hexylthiophene) (P3HT). ${ }^{[2,5]}$ At the same time, structural and electronic disorders are known to be two major hindrances for efficient charge transport properties in polymeric materials. ${ }^{[6,7]}$ High disorder in conducting polymers is mainly due to the random distribution of dopants in the polymer matrix during the fabrication process. Charge transport in conducting and semiconducting polymers is intrinsically highly anisotropic. It is most effective along the chain and the $\pi$-stacking directions. ${ }^{[8-10]}$ This implies that orientation can be an efficient means to improve charge transport in both conducting and semiconducting polymer thin films. Importantly, oriented conducting polymer layers could be of interest as alignment layers for other semiconducting films to fabricate

\author{
Dr. N. Leclerc \\ Université de Strasbourg \\ CNRS \\ ICPEES, UMR 7515 F67000, Strasbourg, France \\ Dr. P. Lévêque, N. Zimmermann \\ Université de Strasbourg \\ CNRS \\ ENGEES, INSA, ICube UMR 7357 F-67000, Strasbourg, France
}


a)

b)

\section{$\mathrm{F}_{4}$ TCNQ (acceptor)}<smiles>CC(C#N)=c1c(F)c(F)c(=C(C#N)C#N)c(F)c1F</smiles>

$\mathrm{E}(\mathrm{eV})$

$$
-5.2
$$

LUMO
P3HT (donor)<smiles></smiles>

\section{$-3.0$}

LUMO

\section{$-5.0$}

HOMO
PBTTT (donor)

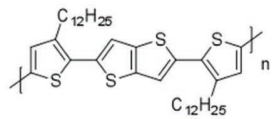

\section{$-3.1$}

LUMO

\section{$-5.2$}

HOMO

HOMO

\section{High-temperature rubbing Doping from solution}
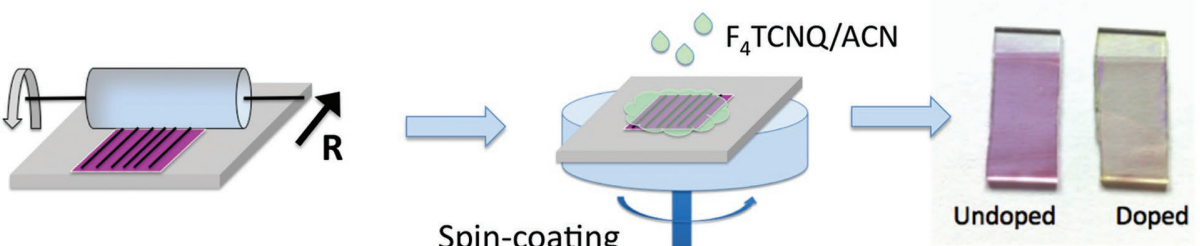

Spin-coating
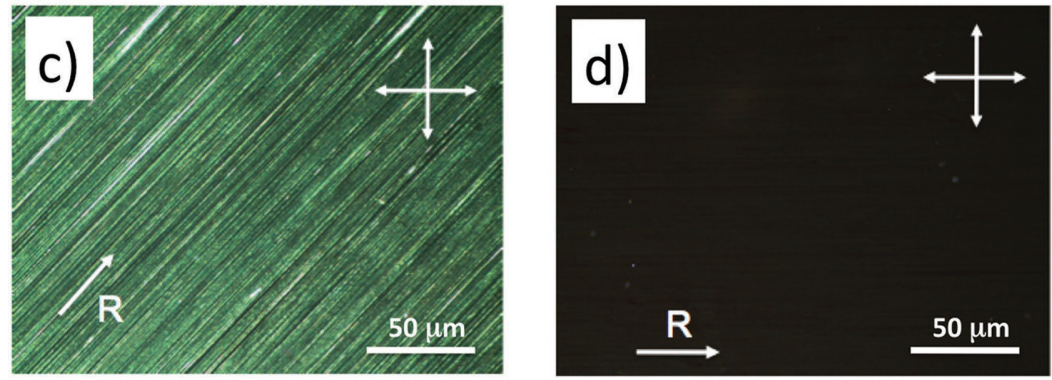

e)
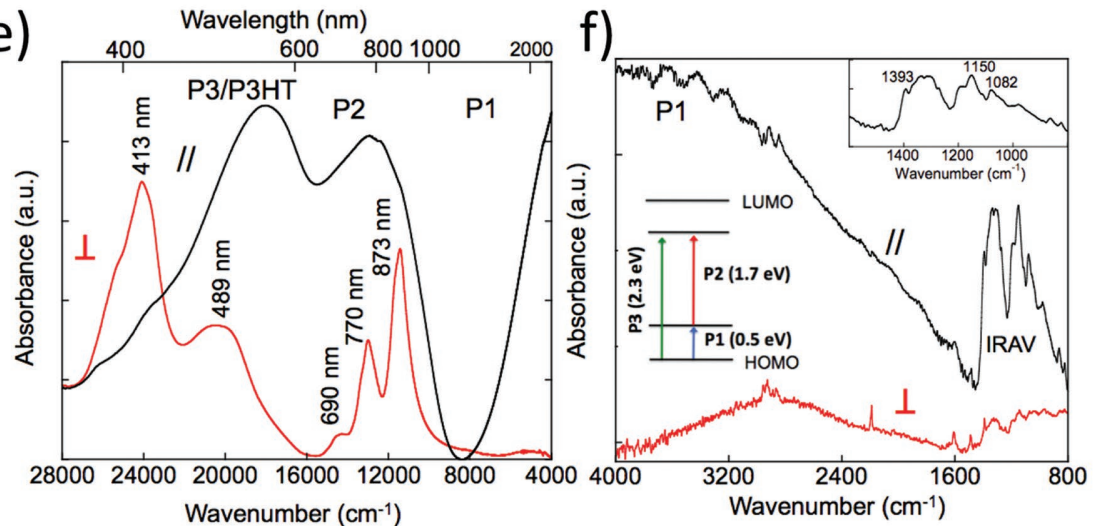

Figure 1. a) Chemical structures and schematic energy diagram of $\mathrm{F}_{4} T C N Q$, $\mathrm{P} 3 \mathrm{HT}$, and PBTTT. b) Two-step preparation method of highly oriented and crystalline conducting polymer films. The first step consists of chain alignment and crystallization of the $\mathrm{P} 3 \mathrm{HT}$ films using high-temperature rubbing ( $R$ is the rubbing direction). The second step implies spin-coating of a solution of $\mathrm{F}_{4}$ TCNQ in acetonitrile (ACN) on the rubbed films. Different concentrations of the initial $F_{4} T C N Q$ solution lead to different doping levels. The picture on the right shows the comparison of the films before and 
polarized light-emitting diodes. ${ }^{[11]}$ At present, methods to prepare highly crystalline and oriented conducting polymer layers are scarce. Orientation of polyacetylene was achieved by various methods, including polymerization under shear flow or in an oriented nematic liquid crystal.[12,13] However, such films present very rough morphologies consisting of large micrometer-scale fibers. ${ }^{[13]}$ Rubbing thin films of PEDOT:PSS leads to surface scratching rather than true chain alignment that is hampered by the strong electrostatic interactions between charged PSS and PEDOT. ${ }^{[14]}$

Controlled doping of crystalline polymer semiconductors appears as a viable alternative approach toward conducting polymers with well-defined structure and electronic properties. Several recent studies on soft doping from solution or from the vapor phase of polymer semiconductors have demonstrated that both elevated charge conductivities and structural control can be obtained. ${ }^{[7,15-17]}$ For instance, Sirringhaus and co-workers have shown that high vacuum sublimation of 2,3,5,6-tetrafluoro-7,7,8,8-tetracyanoquinodimethane ( $\left.\mathrm{F}_{4} \mathrm{TCNQ}\right)$ dopant molecules on poly(2,5-bis(3-dodecylthiophen-2-yl)thieno[3,2-b] thiophene) (PBTTT) films results in conductivities of the order of $250 \mathrm{~S} \mathrm{~cm}^{-1}$. ${ }^{\text {7] }}$ Podzorov and co-workers showed that doping of P3HT and PBTTT with hydrolyzed fluoroalkyl silane (FTS) leads to conductivities of $50 \pm 20$ and $1000 \mathrm{~S} \mathrm{~cm}^{-1}$, respectively. ${ }^{[18]}$ Several groups investigated the doping of P3HT with $\mathrm{F}_{4}$ TCNQ that results in the formation of delocalized charge carriers in the form of polarons or bipolarons. ${ }^{[15-21]}$ UV-vis spectroscopy helped to follow the doping process and to characterize the electronic species resulting from doping. Moreover, such conducting polymers were shown to be interesting materials to fabricate thermoelectric devices as these doped polymer semiconductors show high charge conductivities, high Seebeck constants, and low thermal conductivities. ${ }^{[22,23]}$

On the other side, means exist to control precisely the crystallization and orientation of conjugated polymers such as P3HT or PBTTT. High orientation of polymer semiconductors in thin films was achieved by using various methods including shear coating, ${ }^{[24]}$ stretch alignment, ${ }^{[25]}$ epitaxy, ${ }^{[26]}$ and mechanical rubbing. ${ }^{[27]}$ Rubbing P3HT at temperatures in the $150-240{ }^{\circ} \mathrm{C}$ range results in remarkable alignment with crystallinity exceeding $60 \% .{ }^{[9]}$ Moreover, the lamellar periodicity of the polymer can be precisely controlled by the temperature at which the films are rubbed. ${ }^{[9]}$ Such oriented and crystalline P3HT or PBTTT films are of particular relevance to probe the mechanism of $\mathrm{F}_{4} \mathrm{TCNQ}$ doping on the resulting electrical conductivities and optical properties of the conducting polymer films.

In this contribution, we propose a general method to produce oriented and highly crystalline conducting polymer layers by combining the controlled orientation/crystallization of polymer films by high-temperature rubbing with the soft-doping method by spin-coating a solution of acetonitrile- $\mathrm{F}_{4}$ TCNQ on top of the oriented polymer films. A combination of transmission electron microscopy (TEM), Fourier transform infrared (FTIR) spectra, and UV-vis-near-infrared (NIR) polarized spectroscopies provides compelling evidence for the peculiar orientation of $\mathrm{F}_{4} \mathrm{TCNQ}$ dopants in the polymer matrix and gives new insight in the doping mechanism at play. Finally, the resulting anisotropic optical, charge transport, and thermoelectric properties are demonstrated.

\section{Results and Discussion}

\subsection{Fabrication of Highly In-Plane Oriented Conducting Polymer Films}

Highly oriented and crystalline films of polymer semiconductors, for example, P3HT can be readily prepared by high-temperature rubbing. ${ }^{27,28]}$ When a film of P3HT is rubbed above $150{ }^{\circ} \mathrm{C}$, oriented crystallization parallel to the rubbing direction $R$ sets in and leads to a well-defined semicrystalline lamellar morphology with periodic alternation of crystalline lamellae and amorphous interlamellar zones. Highest crystallinities of up to $60 \%$ are reached for rubbing temperatures close to $220{ }^{\circ} \mathrm{C}$. Therefore, we decided to subject P3HT films rubbed at $220^{\circ} \mathrm{C}$ to soft doping with a solution of $\mathrm{F}_{4} \mathrm{TCNQ}$ in acetonitrile (see Figure 1a,b).

When a $1 \mathrm{mg} \mathrm{mL}-1$ solution of $\mathrm{F}_{4} \mathrm{TCNQ} / \mathrm{ACN}$ is spincoated onto the rubbed films for a few seconds, a rapid change of color is observed as seen in Figure 1b, indicating doping of P3HT with $\mathrm{F}_{4}$ TCNQ. Polarized optical microscopy (POM) shows that the doped films remain birefringent: the pristine orientation of the rubbed layers is not altered upon doping (Figure 1c). The interband optical absorption of P3HT is strongly reduced in the doped films, making these aligned conducting layers almost transparent in the visible range of the spectrum.

\subsubsection{UV-Vis-Near-Infrared (NIR) Spectroscopy}

Polarized UV-vis-NIR spectroscopy confirms the orientation and the doping of the rubbed P3HT films. Figure $1 \mathrm{~d}$ shows the UV-vis-NIR spectra for a P3HT film rubbed at $220^{\circ} \mathrm{C}$ and subsequently doped with a $1 \mathrm{mg} \mathrm{mL}^{-1}$ solution of $\mathrm{F}_{4} \mathrm{TCNQ}$ in ACN. As seen in Figure 1d, the absorption is strongly polarized. The spectra recorded for parallel (POL//) and perpendicular (POL $\perp$ ) orientations have different and characteristic features of doped P3HT and $\mathrm{F}_{4} \mathrm{TCNQ}^{-}$anions, respectively.

For POL//R, the characteristic polaronic bands P1 and P2 located at $\lambda \approx 2500 \mathrm{~nm}(\approx 0.5 \mathrm{eV})$ and $795 \mathrm{~nm}(1.56 \mathrm{eV})$, respectively, result from the doping of $\mathrm{P} 3 \mathrm{HT}$ with $\mathrm{F}_{4} \mathrm{TCNQ}$. The

after doping with $\mathrm{F}_{4}$ TCNQ. c,d) Polarized optical microscopy images under crossed polarizers of the doped polymer films for an aligned and doped P3HT film $\left(T_{R}=220^{\circ} \mathrm{C}, C_{F 4 T C N Q}=1 \mathrm{mg} \mathrm{mL}^{-1}\right)$. Polarizer and analyzer orientations are shown as double arrows. Note the strong birefringence at $45^{\circ}:$ c) while full extinction is observed at $0^{\circ}:$ d) and when the rubbing direction $R$ is set parallel to the polarization of the incident light. e) Polarized UV-Vis-IR spectra of oriented conducting polymer films featuring highly polarized polaronic absorption bands (P1, P2, P3) for incident light polarized parallel to the rubbing direction $(/ /)$ as well as polarized absorption bands of the $\mathrm{F}_{4} \mathrm{TCNQ}^{-}$anions for incident light polarized perpendicular to the rubbing direction $(\perp)$. Included is a schematic energy diagram for the P3HT polaron. f) Polarized FTIR spectra. The infrared active vibration (IRAV) modes are shown as an enlarged view in the inset. 
angular dependence of the intensity of the P1 band was measured and compared to that of the absorption at $600 \mathrm{~nm}$ of the pristine rubbed P3HT films (see Figure S1, Supporting Information). Both curves are perfectly matching and show almost identical full widths at half maximum. Thus, polarized UVvis-NIR shows that the in-plane orientation of P3HT chains is fully maintained upon doping with $\mathrm{F}_{4} \mathrm{TCNQ}$ from a solution in ACN.

For POL//R, the absorption at $570 \mathrm{~nm}$ is close in position to the undoped P3HT but it does not show any vibronic structure. Noteworthy, this band's position is also close to the expected polaronic P3 band $(2.1 \mathrm{eV}) \cdot{ }^{[17]}$ Most interestingly, the P1 and P2 bands are polarized along the rubbing direction with almost no contribution in the direction perpendicular to the rubbing, leading to a dichroic ratio $>50$. This indicates the formation of a metallic-like state in doped P3HT with highly mobile polarons moving essentially along the in-plane direction of P3HT chains (rubbing direction $R$ ).

The spectrum recorded for POL $\perp R$ is very different. It shows the characteristic bands of the $\mathrm{F}_{4} \mathrm{TCNQ}^{-}$anions at 413, 770, and $873 \mathrm{~nm}$ (note that the $413 \mathrm{~nm}$ band is not due to neutral $\mathrm{F}_{4} \mathrm{TCNQ}^{[7]}$ that is characterized by a distinct absorption peak at $383 \mathrm{~nm}$, see Figure S2, Supporting Information). The $\mathrm{F}_{4} \mathrm{TCNQ}^{-}$ bands are quasiabsent in the spectrum obtained for POL//R. Since the transition dipole of the $\mathrm{F}_{4} \mathrm{TCNQ}^{-}$anion is oriented along the long axis of the molecule, ${ }^{[29]}$ this result implies that $\mathrm{F}_{4} \mathrm{TCNQ}^{-}$anions are oriented with their long axis strictly perpendicular to the chain direction of P3HT. This original result is at variance with some postulated structures of $\mathrm{F}_{4}$ TCNQ-doped polymers. In P3HT and PBTTT, the $\mathrm{F}_{4} \mathrm{TCNQ}$ were thought to be intercalated between and oriented parallel to the conjugated polymer backbones with a strong $\pi$-overlap between dopant and polymer. ${ }^{[7]}$ As demonstrated below, the perpendicular orientation of $\mathrm{F}_{4} \mathrm{TCNQ}$ dopants with respect to the polymer chains also holds for other semiconducting polymers such as poly(3octylthiophene) and $\mathrm{C}_{12}$-PBTTT.

For POL $\perp$, the UV-vis-NIR spectra in Figure 1d show a broad contribution at $489 \mathrm{~nm}$, that is, close to the absorption of amorphous P3HT in coiled chain conformation. ${ }^{[27]}$ The absence of significant polaronic absorption and the presence of the absorption band of the amorphous P3HT in the spectra for POL $\perp$ R imply that amorphous interlamellar zones of P3HT are either marginally doped with $\mathrm{F}_{4} \mathrm{TCNQ}$ or that the doped states are strongly localized. Accordingly, it seems that the chain conformation of P3HT is of utmost importance for the doping by $\mathrm{F}_{4}$ TCNQ: planarized rather than coiled chain segments seem necessary for efficient doping.

The quantity of dopants in the films was quantified from the intensity of $\mathrm{F}_{4} \mathrm{TCNQ}^{-}$bands the extinction coefficient of which is known $\left(\varepsilon(873 \mathrm{~nm})=50000 \mathrm{~mol} \mathrm{~L}^{-1} \mathrm{~cm}^{-1}\right) \cdot{ }^{[31]}$ Typically, P3HT films rubbed at $220{ }^{\circ} \mathrm{C}$ and doped with a $1 \mathrm{mg} \mathrm{mL}^{-1} \mathrm{~F}_{4} \mathrm{TCNQ} /$ ACN solution are characterized by a doping ratio of $17 \%-19 \%$ $\mathrm{F}_{4}$ TCNQ molecules per 3-hexylthiophene monomer. ${ }^{[30]}$ This value is fully consistent with the reported values for solution cast doped P3HT films. ${ }^{[15]}$

Further essential information on the doped P3HT films is obtained by using polarized FTIR spectroscopy (see Figure 1e). In the range $1500-4000 \mathrm{~cm}^{-1}$, the spectrum shows the characteristic P1 polaronic band polarized parallel to the rubbing direction. For the polarization perpendicular to the chains, a broadband of weak intensity and centered around $2800 \mathrm{~cm}^{-1}$ is recorded. In the range $1500-800 \mathrm{~cm}^{-1}$, the spectrum shows a set of very intense infrared active vibrational (IRAV) modes for $\mathrm{POL} / / \mathrm{R}$ that are absent for POL $\perp \mathrm{R}$. These peaks are absent in the pristine rubbed P3HT films and do not coincide with peaks from the $\mathrm{F}_{4} \mathrm{TCNQ}^{-}$anion. ${ }^{[32]}$ Recent studies on PCPDTBT/ $\mathrm{F}_{4}$ TCNQ, P3HT/FTS, or poly(3-decylthiophene) (P3DT)/NOPF 6 have evidenced similar FTIR signatures. ${ }^{[33,34]}$ The IR spectrum of poly(3-decylthiophene) ${ }^{+}$cations in $\mathrm{CDCl}_{3}$ in the range $1000-1500 \mathrm{~cm}^{-1}$ is quite similar to that of P3HT films doped with $\mathrm{F}_{4} \mathrm{TCNQ}$. The observed intensity enhancement of absorption is assigned to the presence of dopant-induced hole polarons on the polymer chain. ${ }^{[32,33]}$ Further density functional theory (DFT) calculations by Nuzzo et al. indicate that such IRAV modes are well accounted for by considering the formation of dopant/polymer complexes. ${ }^{[33]}$

\subsubsection{Structure of Doped P3HT Films}

TEM was used to evaluate the impact of doping on the thin film structure (see Figure 2). From a morphological point of view, the pristine films rubbed at $220{ }^{\circ} \mathrm{C}$ show the periodic lamellar structure with alternation of crystalline and amorphous domains. TEM bright field (BF) shows that the doping does not alter this lamellar semicrystalline structure. The total lamellar period is unchanged after doping (23 nm, see Figure S3, Supporting Information). In addition, the semicrystalline structure of the doped films is also observed in high-resolution TEM (HRTEM). As seen in Figure 2c, face-on crystals showing a characteristic fringed pattern alternate with amorphous areas. Accordingly, doping does not disrupt the layered structure of P3HT consisting of planes of $\pi$-stacked backbones that alternate with layers of alkyl side chains. The major effect of doping is on the periodicity along the side chains that increases to 17.4-17.8 $\AA$ versus $16.6 \AA$ in the pristine P3HT films. Overall, the TEM observations indicate that the nanomorphology of the oriented and crystalline pristine P3HT films is well preserved upon doping with $\mathrm{F}_{4}$ TCNQ.

Electron diffraction (ED) was used to probe the impact of doping on the crystal structure. Figure 2a,b compares the ED patterns of doped ( $\left.1 \mathrm{mg} \mathrm{mL} \mathrm{L}^{-1} \mathrm{~F}_{4} \mathrm{TCNQ} / \mathrm{ACN}\right)$ and undoped rubbed P3HT films. Most interestingly, the doped samples display a well-defined ED pattern revealing high order after doping with $\mathrm{F}_{4} \mathrm{TCNQ}$. The pattern is in essence quite similar to that of the undoped film. The presence of both $h 00(h=1-3)$ and 020 equatorial reflections indicates that the films consist of face-on and edge-on oriented crystals. Careful analysis shows that the 002 reflection along the rubbing direction is unaltered in position and intensity after doping, showing that doping did preserve both the aligned character of the films (consistent with POM and spectroscopic observations) and the crystalline order along the chain direction. A slight loss in intensity of the 102 and 202 reflections suggests some disorder introduced in the arrangement of side chains. In the direction perpendicular to the polymer chains, the equatorial 020 and the $h 00$ reflections $(h=1-3)$ reveal a change in unit cell parameters after doping. Typically, the layer period 

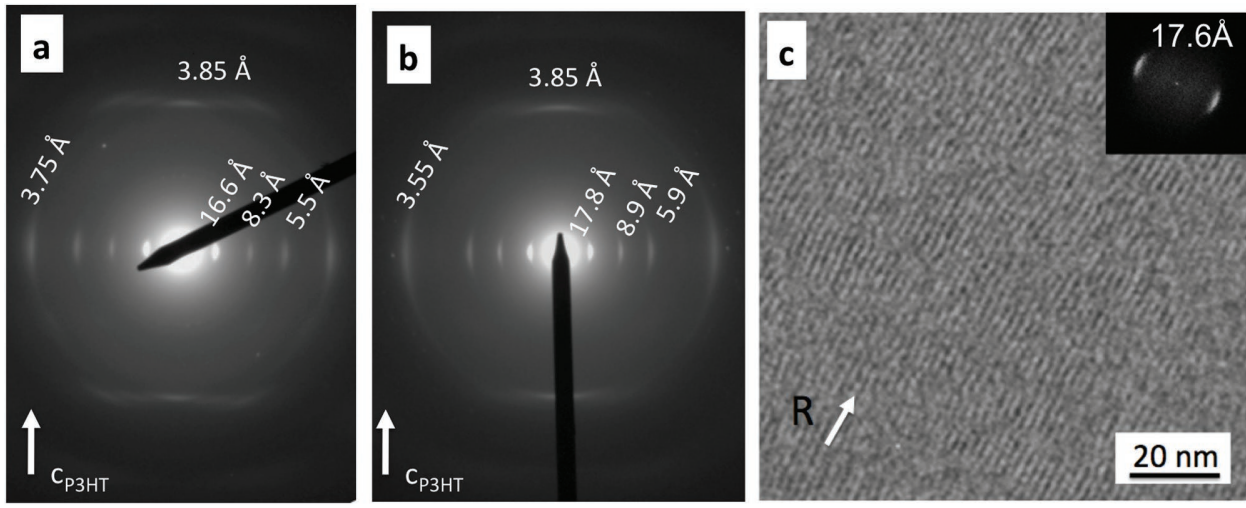

d

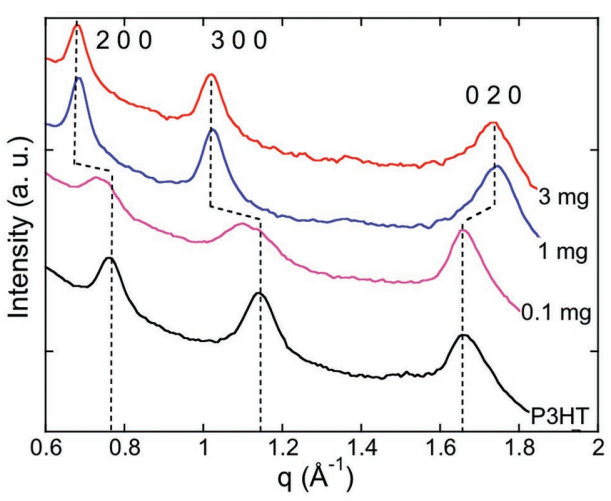

f

Pristine P3HT (Form I)
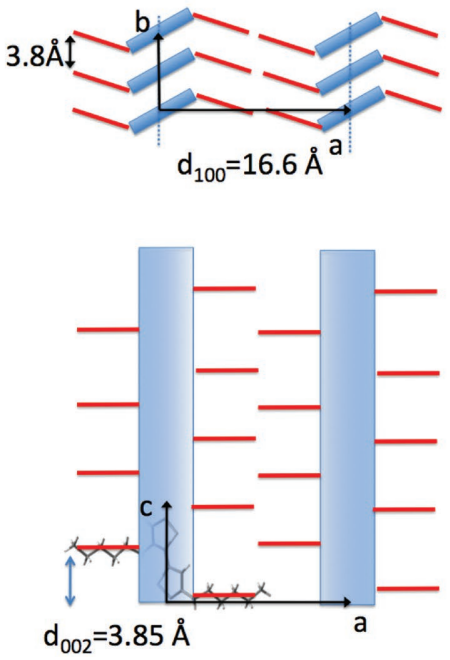

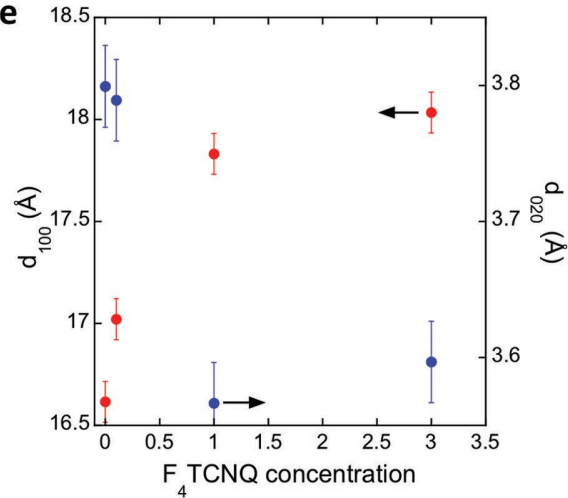

$\mathrm{F}_{4}$ TCNQ-doped P3HT

\section{$\widehat{\Phi}$}
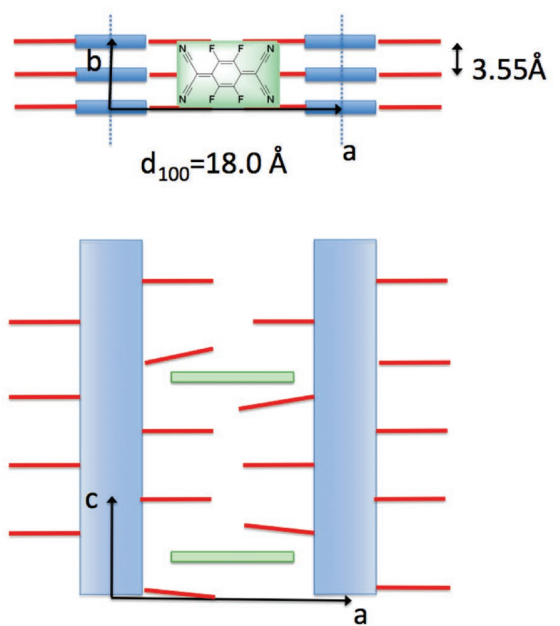

Figure 2. Evolution of the structure of oriented $\mathrm{P} 3 \mathrm{HT}$ films upon doping with $\mathrm{F}_{4} \mathrm{TCNQ}$. a) Electron diffraction pattern of a pristine film $\left(T_{R}=220^{\circ} \mathrm{C}\right)$, b) of the doped thin film, and c) HRTEM of a film after doping with $1 \mathrm{mg} \mathrm{mL}^{-1}$ solution of $\mathrm{F}_{4}$ TCNQ in acetonitrile. The inset in the HRTEM image corresponds to a FFT pointing at an interlayer spacing of $17.6 \AA$. d) Intensity profile along the equator of the ED pattern for films doped at different concentrations of $\mathrm{F}_{4} \mathrm{TCNQ}$. e) Evolution of the layer spacing $d_{100}$ and the $\pi$-stacking period $d_{020}$ as a function of the doping level. $\mathrm{f}$ ) Schematic illustration of the structural change in the packing of $\mathrm{P} 3 \mathrm{HT}$ chains induced by doping with $\mathrm{F}_{4} \mathrm{TCNQ}$. The structures correspond to the pristine form I of undoped $\mathrm{P} 3 \mathrm{HT}^{[35]}$ and the structure after doping with a $3 \mathrm{mg} \mathrm{mL}^{-1}$ solution.

$d_{100}$, that is, the distance between polymer chains separated by alkyl side chains, increases from $16.6 \AA$ in pristine films to 17.6-18.0 ^ after doping (consistent with HRTEM). The $\pi$-stacking distance shows an opposite trend and decreases from 3.75 to $3.55 \AA$ after doping. The analysis of the ED pattern shows that there is no coexistence of the doped and undoped phases of P3HT since the $16.6 \AA$ reflection is absent from the ED patterns of samples doped with $\mathrm{F}_{4} \mathrm{TCNQ}$ at a concentration above $0.5 \mathrm{mg} \mathrm{mL}^{-1}$. Accordingly, doped P3HT films consist of only one type of crystalline domains with an expanded unit cell parameter and reduced $\pi$-stacking distance (reduced $b$-axis parameter), the $c$-axis remaining unaltered. This implies 
further that the presence of absorption features around $570 \mathrm{~nm}$ corresponding to "undoped" P3HT is not associated with the pristine undoped form I of P3HT but should be attributed to undoped P3HT chain segments within the crystals of the doped phase.

\subsection{Influence of Doping Level}

\subsubsection{UV-Vis-NIR Spectroscopy}

Further insight in the doping mechanism is obtained by following the spectroscopic and structural variations of rubbed P3HT films with increasing dopant level. The doping level is readily controlled by adjusting the concentration of the $\mathrm{F}_{4}$ TCNQ/ACN solution from 0.01 to $3 \mathrm{mg} \mathrm{mL}^{-1}{ }^{[16]}$ Figure $2 \mathrm{e}$ shows the evolution of reticular distances $d_{100}$ and $d_{020}$ extracted from the ED patterns as a function of increasing dopant concentration whereas Figure 3 shows the evolution of the UV-vis spectrum as a function of increasing dopant concentration for the incident light polarized parallel and perpendicular to the chain direction for the rubbed P3HT films.

As expected, the intensities of the characteristic absorption peaks of both the polaron and the $\mathrm{F}_{4} \mathrm{TCNQ}^{-}$anions increase with the concentration of $\mathrm{F}_{4} \mathrm{TCNQ}$ in ACN. Even for dopant concentrations as low as $0.01 \mathrm{mg} \mathrm{mL} \mathrm{m}^{-1}$, typical signatures of P3HT polarons and $\mathrm{F}_{4} \mathrm{TCNQ}^{-}$anions are observed, indicating charge transfer between P3HT and $\mathrm{F}_{4}$ TCNQ. In addition, the polaron bands are already strongly polarized parallel to the chain direction. However, in the range of dopant concentration $0.01-0.1 \mathrm{mg} \mathrm{mL} \mathrm{m}^{-1}$, the crystal structure of the films changes only marginally. The interlayer spacing $d_{100}$ and the $\pi$-stacking periods $d_{020}$ are almost equal to the values of pristine P3HT. The broadening of the $h 00$ peaks observed for $C_{\mathrm{F} 4 \mathrm{TCNQ}}=0.1 \mathrm{mg} \mathrm{mL}^{-1}$ may indicate some possible disorder induced in P3HT crystals upon doping.

At high doping concentrations of $\left(\geq 3 \mathrm{mg} \mathrm{mL}^{-1}\right)$, a saturation and even a slow decrease in intensity of the anion absorption and polaron peaks are observed. At the same time, TEM indicates that both the interlayer spacing and the $\pi$-stacking periods saturate at 18.0 and $3.55 \AA$, respectively. Incidentally, the surface of the films doped at $3 \mathrm{mg} \mathrm{mL}^{-1}$ shows the presence of excess $\mathrm{F}_{4}$ TCNQ crystallites.

The evolution of the UV-vis spectrum for POL $\perp$ R as a function of doping level is also very instructive, especially in the 350-650 $\mathrm{nm}$ range where the spectrum results from the overlap of the broad absorption of amorphous P3HT (520 nm) and the absorption bands of $\mathrm{F}_{4} \mathrm{TCNQ}^{-}$. The evolution with dopant concentration allows to further assess the attribution of the bands. The $413 \mathrm{~nm}$ band of $\mathrm{F}_{4} \mathrm{TCNQ}^{-}$clearly increases with doping
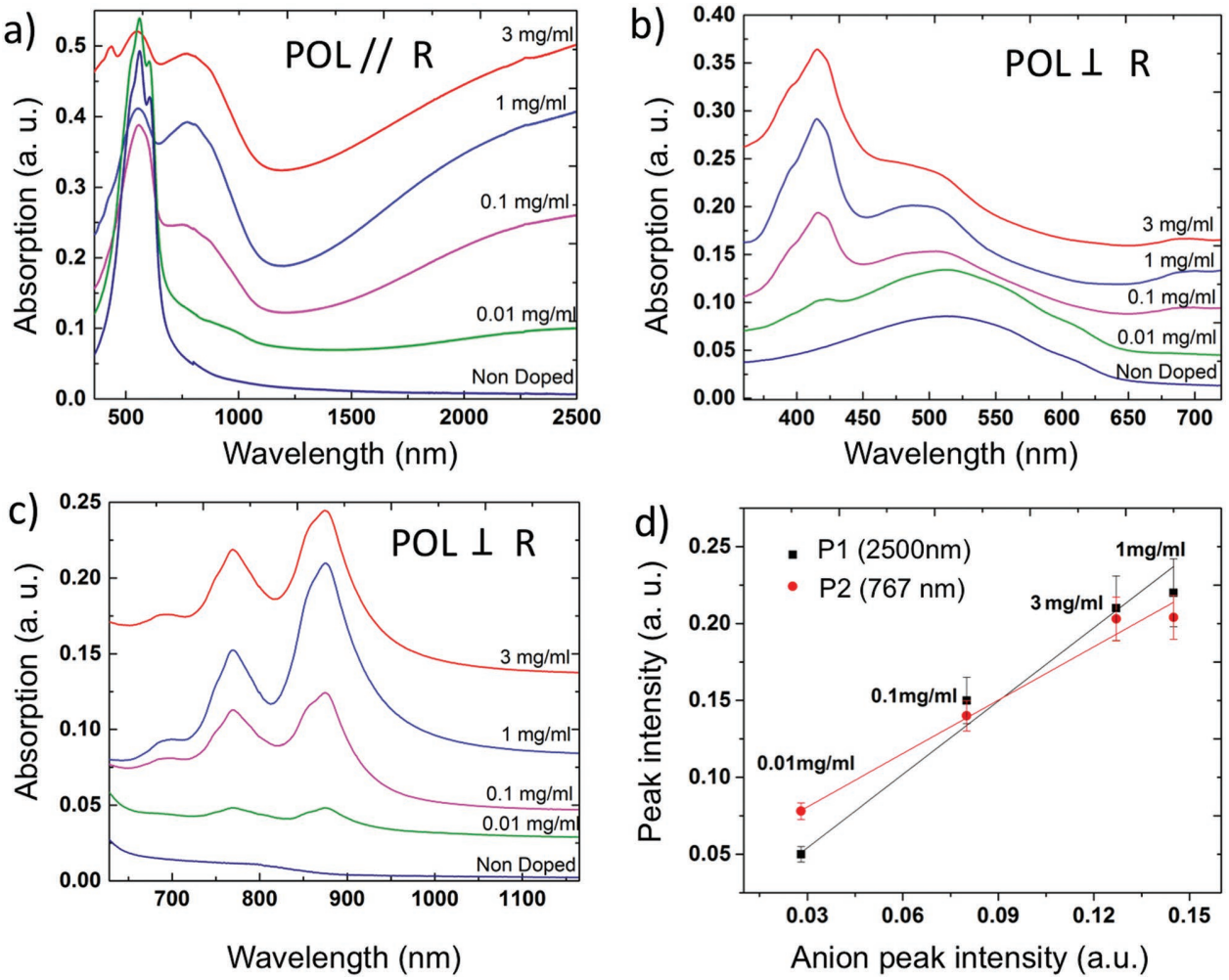

Figure 3. Evolution of the UV-vis-NIR spectrum of highly oriented P3HT films (rubbed at $220^{\circ} \mathrm{C}$ ) as a function of the $\mathrm{F}_{4} \mathrm{TCNQ}$ concentration in $A C N$. The spectra are recorded for different polarizations of the incident light $(\mathrm{POL})$ with respect to the rubbing direction $(R)$. For clarity, the spectra for different concentrations are shifted along the ordinate axis. a) $\mathrm{PO} / / \mathrm{R}, \mathrm{b}) \mathrm{POL} \perp \mathrm{R}$ and spectral range showing the broad absorption of amorphous $\mathrm{P} 3 \mathrm{HT}$ $(480-520 \mathrm{~nm})$ and the $413 \mathrm{~nm}$ peak characteristic of the oriented $\mathrm{F}_{4} \mathrm{TCNQ}^{-}$anions, c) POL $\perp R$ and spectral range showing the spectral signatures of oriented $\mathrm{F}_{4} \mathrm{TCNQ}^{-}$anions. d) Linear dependence between the intensities of the polaron $\mathrm{P} 1$ and $\mathrm{P} 2$ peaks and the intensity of the $\mathrm{F}_{4} \mathrm{TCNQ}^{-}$anions peak at $880 \mathrm{~nm}$. The full lines are the results of the linear fits. 
concentration. By contrast, the absorption of the amorphous interlamellar zones around $525 \mathrm{~nm}$ remains almost unaffected by the doping: there is only a small blue-shift to $489 \mathrm{~nm}$ and its intensity remains relatively constant (Figure 3b). This supports the previous observation that doping of P3HT with $\mathrm{F}_{4} \mathrm{TCNQ}$ concerns mainly planarized chain segments in the crystalline domains.

Most importantly, the fact that the P3HT polaron and the $\mathrm{F}_{4} \mathrm{TCNQ}^{-}$bands have orthogonal polarizations eases the quantification of these species and helps establish correlations between them. In Figure 3d, the intensity of each of the P1 and $\mathrm{P} 2$ polaron bands is proportional to the absorbance of the $\mathrm{F}_{4} \mathrm{TCNQ}^{-}$anion, that is, to the quantity of anions in the films. This result supports an integer charge transfer between P3HT and $\mathrm{F}_{4} \mathrm{TCNQ}$ for all doping levels investigated herein. ${ }^{[15,19]}$ More importantly, it underlines the possibility to control quite reproducibly the levels of doping in such oriented polymer films. Moreover, the absorbance of $\mathrm{F}_{4} \mathrm{TCNQ}^{-}$anions tends to level for solutions with a concentration beyond $1 \mathrm{wt} \%$, suggesting that a maximum doping concentration is indeed reached for this film processing. This is further supported by the presence of small pristine $\mathrm{F}_{4} \mathrm{TCNQ}$ crystals on the surface of the doped films for $3 \mathrm{wt} \%$ (similar to those observed previously in vapor-phase-doped PBTTT films $\left.{ }^{[7]}\right)$.

\subsubsection{Structure of Doped Polymers Films}

TEM was used to follow the evolution of the structure with the level of doping. Figure 2e shows the variation of the layer period along the alkyl side chain $d_{100}$ and the $\pi$-stacking period $d_{020}$ as a function of concentration of dopants. The section profile of the ED patterns along the equator is shown in Figure $2 \mathrm{~d}$ as it features the evolution of the characteristic 200,300 , and 020 ( $\pi$-stacking) peaks as a function of doping concentration. Both periodicities vary with the concentration of dopants. The higher the doping level, the higher the value of $d_{100}$ and the lower the $\pi$-stacking period. The structure of P3HT changes continuously with the concentration of dopants incorporated into the films following the scheme illustrated in Figure 2f. Both the $\pi$-stacking and the $d_{100}$ period change simultaneously with doping concentration. This result is at variance with the case of $\mathrm{F}_{4}$ TCNQ-doped PBTTT reported by Kang et al. who suggested that the incorporation of dopants in the layers of side chains results only in the expansion of the $\left(\begin{array}{lll}1 & 0 & 0\end{array}\right)$ period. In the present case, the $\pi$-stacking is also affected. ${ }^{[7]}$

Our results suggest that a threshold concentration of dopants is necessary to induce the structural change to the doped phase with incorporation of $\mathrm{F}_{4} \mathrm{TCNQ}^{-}$anions in the layers of alkyl side chains. As seen in Figure 2d, the $h 00$ spacings remain virtually unchanged up to a doping concentration of $0.1 \mathrm{mg} \mathrm{mL} \mathrm{m}^{-1}$. However, even for such a low doping concentration, the intensities are reduced and the $h 00$ peaks are substantially broadened. As opposed to this, even for a concentration as low as $0.5 \mathrm{mg} \mathrm{mL}-1$, the $h 00$ reflections are shifted to lower $q$ values and become very sharp and intense. The change in peak position indicates an expansion of the unit cell along the side chains. The relative intensity ratio between the 100,200 , and 300 reflections changes with doping concentration. The intensity of the 300 reflection is strongest for $3 \mathrm{mg} \mathrm{mL}^{-1}$. This change reflects variations in the distribution of electron density in the unit cell as a consequence of the presence of variable amounts of $\mathrm{F}_{4} \mathrm{TCNQ}$ molecules in the lattice of the doped phase. The change is further evidence for a progressive structural modification upon incorporation of $\mathrm{F}_{4} \mathrm{TCNQ}$ molecules in the alkyl side chain layers, in agreement with the progressive change in $a$ and $b$ unit cell parameters.

\subsection{Doping of Other Semiconducting Polymers}

\subsubsection{Family of Poly(3-alyklthiophene)s}

The same alignment and doping protocol was applied to other semiconducting polymers to validate its generality. First, we have considered the family of poly(3-alkylthiophene)s in order to see if the length of the side chains influences on the doping mechanism/efficiency. Therefore, oriented films of poly(3butylthiophene) (P3BT) and poly(3-octylthiophene) (P3OT) were subjected to the same doping method with $\mathrm{F}_{4}$ TCNQ in ACN $\left(1 \mathrm{mg} \mathrm{mL}^{-1}\right)$. Figure 4 depicts the change in ED pattern for P3BT and P3OT as a function of doping with $\mathrm{F}_{4}$ TCNQ and indicates the same trend as observed for P3HT. The orientation of the films is maintained after doping and the structure of crystals is modified with an expansion of the lattice along the alkyl side chains and a contraction along the $\pi$-stacking direction. In P3OT, the unit cell expands along the side chains from 20.1 to $22.6 \AA$ as compared to 12.6 to $14.0 \AA$ for P3BT. In both cases, the $\pi$-stacking reduces to a similar value of $3.55 \AA$. For P3OT, polarized UV-vis-NIR spectroscopy (see Figure 4f) evidences a situation similar to that for P3HT. The absorption bands of the $\mathrm{F}_{4} \mathrm{TCNQ}^{-}$anions are polarized in the direction perpendicular to the backbone of P3OT whereas the polaron bands P1 and P2 are only seen for POL//R. The situation for P3BT is different. As seen in Figure 4c, the polaron bands are polarized along the rubbing direction but the absorption bands of the $\mathrm{F}_{4} \mathrm{TCNQ}^{-}$anions are not polarized. The characteristic bands of $\mathrm{F}_{4} \mathrm{TCNQ}^{-}$have similar intensities for POL//R and $\mathrm{POL} \perp \mathrm{R}$. This indicates that $\mathrm{F}_{4} \mathrm{TCNQ}^{-}$anions are more randomly oriented to the polymer backbone of P3BT. Clearly, the length of the alkyl side chains in P3ATs influences the organization of $\mathrm{F}_{4} \mathrm{TCNQ}^{-}$anions in the layers of alkyl side chains and its orientation perpendicular to the conjugated polythiophene backbones.

\subsubsection{Doping of PBTTT}

To validate the fabrication method of highly oriented conducting polymer films, we also prepared doped films of a different polythiophene, namely, $\mathrm{C}_{12}$-PBTTT. Figure $4 \mathrm{i}$ shows the polarized UV-vis-NIR spectrum of $\mathrm{C}_{12}$-PBTTT films rubbed at $150{ }^{\circ} \mathrm{C}$ and subsequently doped with a solution of $\mathrm{F}_{4}$ TCNQ in ACN $\left(1 \mathrm{mg} \mathrm{mL}^{-1}\right)$. As for P3HT, the polaron bands are seen for $\mathrm{POL} / / \mathrm{R}$ whereas bands of the $\mathrm{F}_{4} \mathrm{TCNQ}^{-}$anions are observed for POL $\perp R$. Both POM and ED show that the $\mathrm{C}_{12}$-PBTTT chain orientation is maintained after doping. However, ED reveals substantial structural changes in the films upon doping. Overall, the ED reflections of the doped films show a strong intensity reduction (compare Figure $4 \mathrm{~g}$ with Figure $4 \mathrm{~h}$ ) except 
P3BT
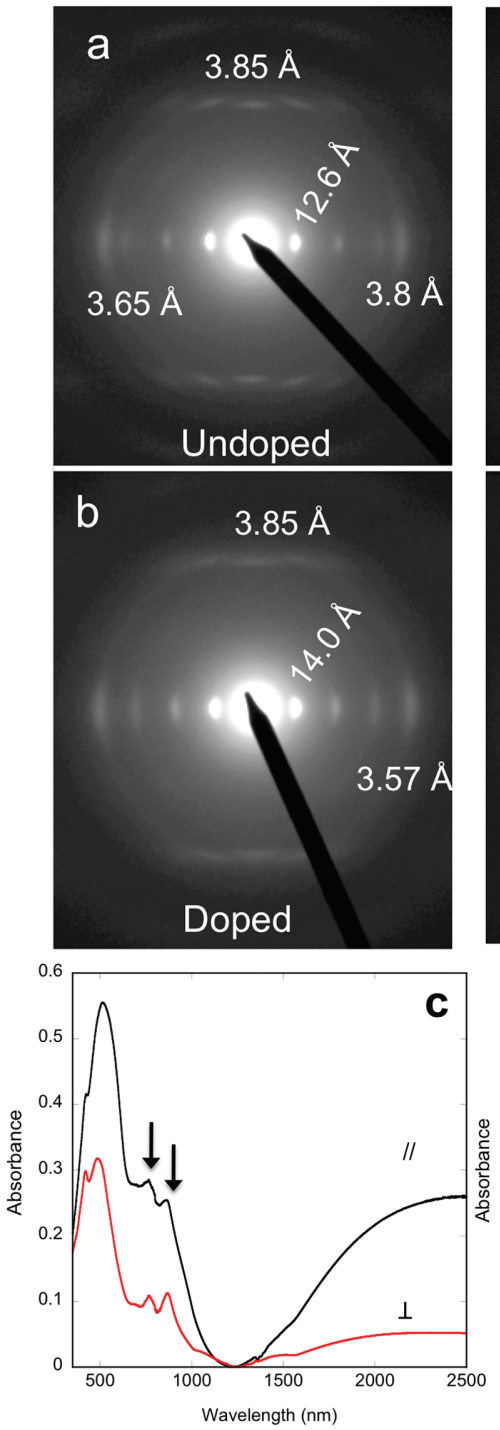

P3OT
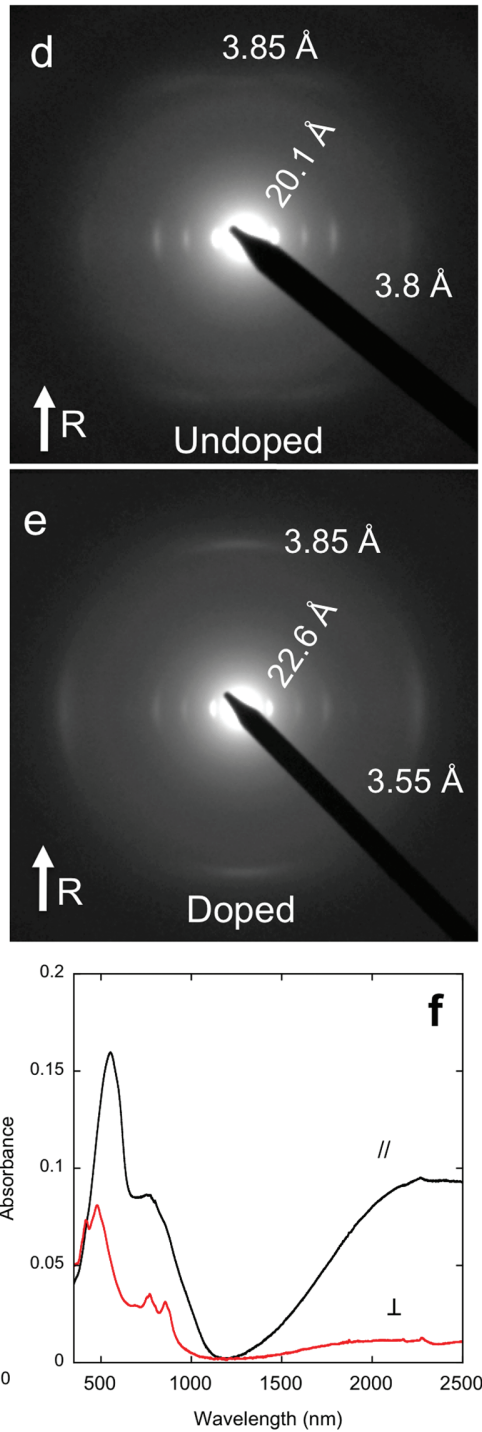

PBTTT
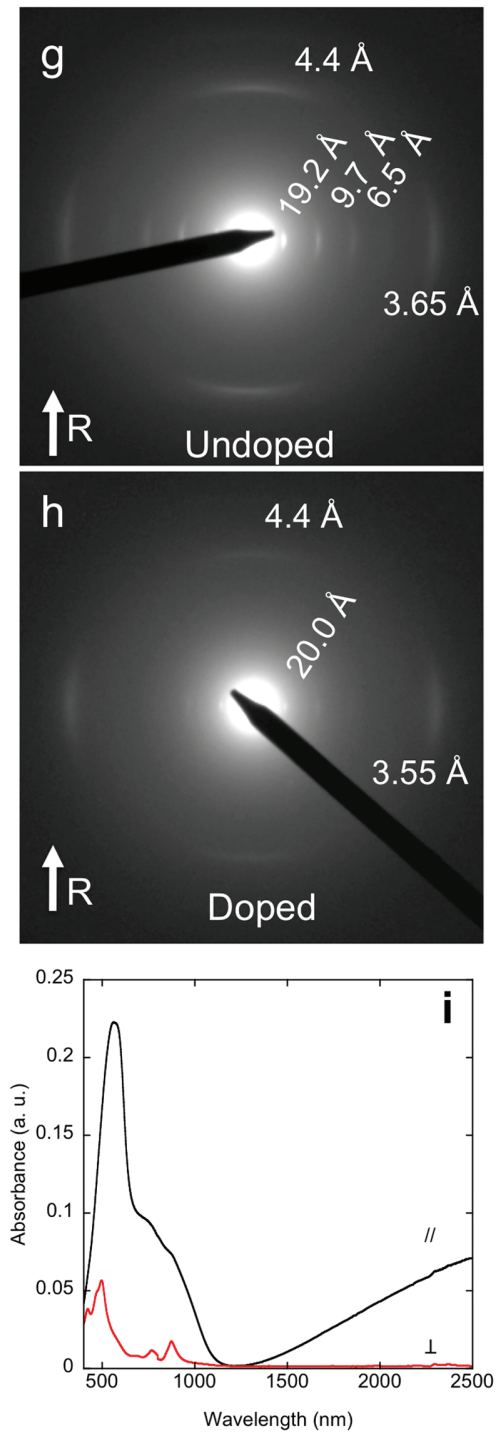

Figure 4. Electron diffraction patterns of various oriented semiconducting polymers in pristine and doped forms and polarized UV-Vis-NIR absorption spectra (// stands for the incident light polarized along the chain direction and $\perp$ for incident light polarized perpendicular to the chain direction): $\mathrm{a}-\mathrm{c}$ ) regioregular poly(3-butylthiophene) (P3BT), d-f) regioregular poly(3-octylthiophene) (P3OT), and g-i) poly(2,5-bis(3-dodecylthiophen-2-yl) thieno[3,2-b] thiophene) ( $\mathrm{C}_{12}$-PBTTT). $R$ stands for the direction of rubbing. In (c) the two arrows point at the absorption peaks of $\mathrm{F}_{4} \mathrm{TCNQ}^{-}$anions in the spectrum of doped P3BT for both POL//R and POL $\perp R$.

the enhanced intensity of the $\pi$-stacking reflection. These variations indicate that the dominant face-on orientation of $\mathrm{C}_{12}$ PBTTT crystals in rubbed films has changed after doping to a dominant edge-on orientation. A similar domain reorientation was observed upon thermal annealing of rubbed $\mathrm{C}_{12}$-PBTTT films. ${ }^{[28]}$ Regarding the unit cell parameters, doping $\mathrm{C}_{12}$-PBTTT with $\mathrm{F}_{4}$ TCNQ results in a reduced $\pi$-stacking periodicity of $3.55 \AA$ (vs $3.65 \AA$ in pristine $\mathrm{C}_{12}$-PBTTT films) and a moderate expansion along the side chains from 19.2 to $20.0 \AA$. Accordingly, much like the P3ATs, $\mathrm{F}_{4}$ TCNQ doping of $\mathrm{C}_{12}$-PBTTT also generates oriented thin films with a modified unit cell (expanded $a$-axis, reduced $b$-axis ( $\pi$-stacking), and unaltered $c$ axis parameters).

\subsection{Anisotropy of Charge Transport and Seebeck Coefficient}

The ability to obtain highly oriented crystalline films of conducting polymers provides a means to investigate the anisotropy of both charge conductivity and thermoelectric properties. Both, charge conductivity $\sigma$ and the Seebeck coefficient $S$ can be measured along the rubbing direction and perpendicular to it. The Seebeck coefficient characterizes the heat transported by thermally excited charge carriers. ${ }^{[36,37]}$ The transported heat depends on the band structure and scattering events of the material. Conjugated polymers such as P3HT and $\mathrm{C}_{12}$-PBTTT show a substantial anisotropy of charge mobility that is highest along the chain direction and the $\pi$-stacking direction ( $b$-axis) and 

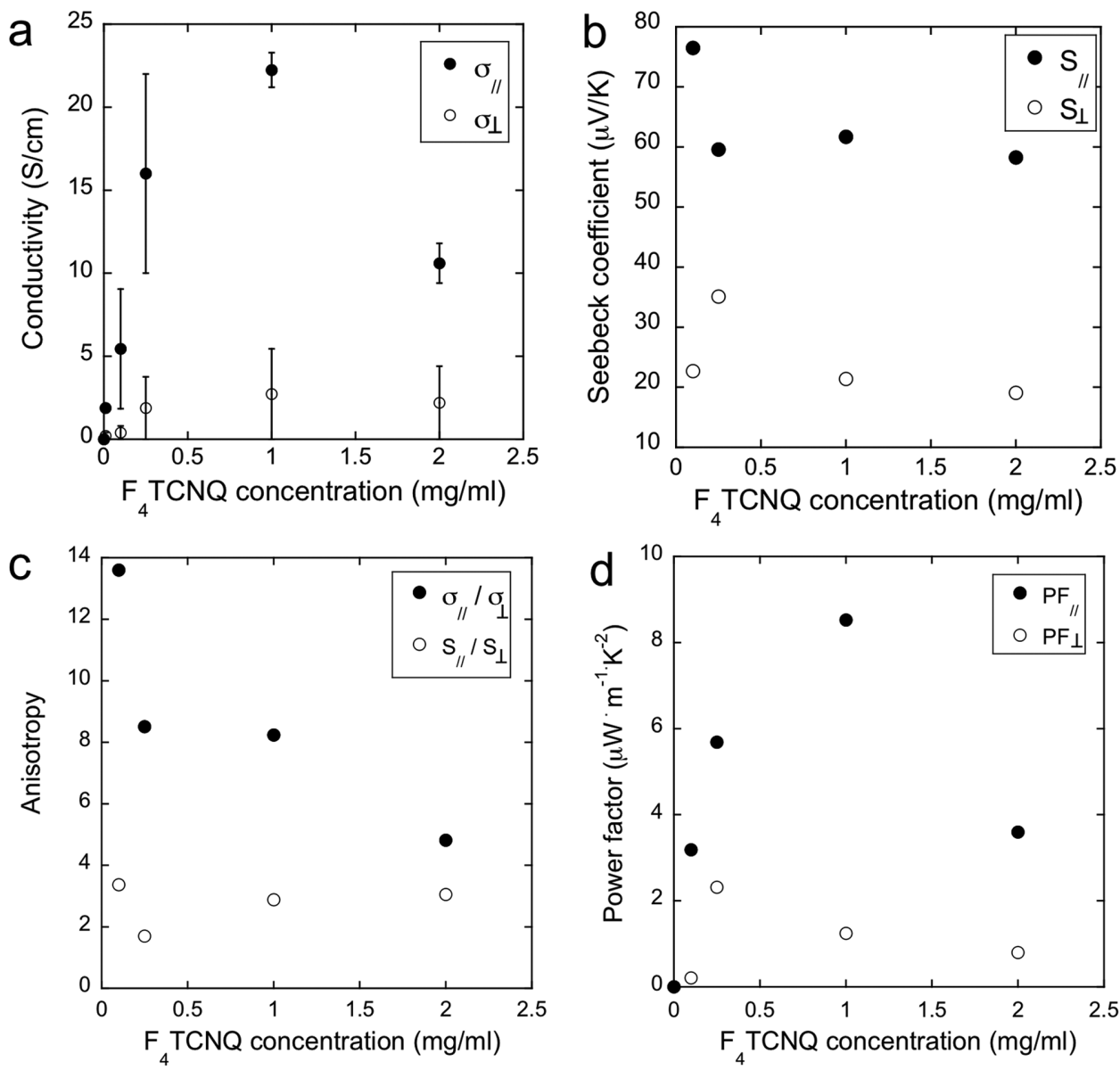

Figure 5. Evolution of the anisotropic conductivity and thermoelectric properties for rubbed P3HT films $\left(T_{R}=220^{\circ} \mathrm{C}\right)$ doped with $\mathrm{F}_{4} \mathrm{TCNQ}$ at different concentrations. a) Conductivity, b) Seebeck coefficient, c) anisotropy of the conductivity and Seebeck coefficient, and d) power factor. All values were measured parallel to the rubbing direction $(/ /)$ and perpendicular to the rubbing direction $(\perp)$.

negligible along the alkyl side chains (a-axis of the crystal). ${ }^{[27]}$ The strong polarization of the polaronic absorption of doped P3HT films suggests that polarons move mainly along the rubbing direction, which should translate in a corresponding anisotropy of both charge conductivity and thermoelectric properties. Yet, no measure of the anisotropy of thermoelectric properties in oriented conducting polymers is available. Accordingly, we have measured the values of the charge conductivity $\sigma$ and Seebeck coefficient $S$ for different P3HT samples rubbed at $220{ }^{\circ} \mathrm{C}$ and subsequently doped with $\mathrm{F}_{4} \mathrm{TCNQ} / \mathrm{ACN}$ solutions of different concentrations. Figure $5 \mathrm{a}, \mathrm{b}$ shows the evolution of the charge conductivity $\sigma_{/ /}$and $\sigma_{\perp}$ as well as the Seebeck coefficients $S_{/ /}$and $S_{\perp}$. Both $S$ and $\sigma$ are measured in the direction parallel and perpendicular to the rubbing direction $R$ as a function of the doping concentration of $\mathrm{F}_{4}$ TCNQ. Highest values of $\sigma$ and $S$ are always observed in the rubbing direction (polymer chain direction). The conductivity $\sigma_{/ /}$increases to a value of $22 \pm 5 \mathrm{~S} \mathrm{~cm}^{-1}$ for $1 \mathrm{mg} \mathrm{mL}^{-1}$ and tends to decrease beyond that concentration whereas the Seebeck coefficient $S_{/ /}$is much less dependent on the doping concentration and levels at a value in the range (58-62) $\mu \mathrm{V} \mathrm{K}^{-1}$ for $C_{\mathrm{F} 4 \mathrm{TCNO}} \geq 0.25 \mathrm{mg} \mathrm{mL}^{-1}$. As compared to a nonoriented P3HT film, the Seebeck coefficient is enhanced along the rubbing direction by a factor of 1.5-2.0 whereas the charge conductivity is also improved by a factor 3.5-4.0.

As seen from Figure 5c, a clear anisotropy of both $\sigma$ and $S$ is observed in the aligned films. At all doping concentrations, the anisotropy of the Seebeck coefficient $a_{\mathrm{S}}=S_{/ /} / S_{\perp}$ is smaller than the anisotropy of the charge conductivity $a_{\sigma}=\sigma_{/ /} / \sigma_{\perp}$, typically $a_{\mathrm{S}} \approx 3$ versus $a_{\sigma}=8-10$ (see Figure $5 \mathrm{c}$ ). For the conductivity, the anisotropy decreases when the doping concentration increases whereas the Seebeck constant is little affected by the doping concentration.

Most interesting for thermoelectric applications is the power factor given by the formula $P F=\sigma S .{ }^{[2]}$ As seen in Figure $5 d$, $\mathrm{PF}$ is enhanced along the rubbing direction and reaches a value of $\approx 8.5 \mu \mathrm{W} \mathrm{m}{ }^{-1} \mathrm{~K}^{-2}$ for $C_{\mathrm{F} 4 \mathrm{TCNQ}}=1 \mathrm{mg} \mathrm{mL}^{-1}$ which is of the same order of magnitude as that obtained in PEDOT:PSS thin films $\left(24 \mu \mathrm{W} \mathrm{m} \mathrm{m}^{-1} \mathrm{~K}^{-2}\right) \cdot{ }^{[38]}$ The simultaneous enhancement of $\sigma$ and $S$ via polymer alignment is interesting from the point of view of thermoelectric properties. Indeed, usually, $S$ and $\sigma$ are linked by the relation $S \propto \sigma^{-1 / 4}{ }^{[22,23]}$ Therefore, when the charge conductivity is increased with the dopant concentration, one observes a corresponding drop of the Seebeck constant. Because of this correlation between $S$ and $\sigma$, an optimum doping concentration is necessary to maximize the 
power factors PF of TE devices. ${ }^{[22,23]}$ In the present case, alignment of the polymer films allows to increase both $\sigma$ and $S$ in the direction of the polymer chains. Therefore, a strategy of aligning conducting polymers can help enhance thermoelectric efficiency of polymer TE devices under the condition that the heat conductivity is not substantially enhanced along the chain direction.

\section{Discussion}

The impact of dopant concentration on the film structure uncovered in the present investigation helps clarify the mechanism of doping of P3ATs by $\mathrm{F}_{4}$ TCNQ. Two regimes of doping can be distinguished. For $C_{\mathrm{F} 4 \mathrm{TCNQ}} \leq 0.1 \mathrm{mg} \mathrm{mL}^{-1}$, the structure of the P3HT films is marginally modified although spectral signatures of doped species are observed. This result suggests that a surface doping mechanism is possibly at play without incorporation of dopants in the layers of side chains of the polymers. This situation is similar to the doping of P3HT with a surface layer of hydrolyzed fluoroalkyl trichlorosilane. ${ }^{[18]}$

For $C_{\mathrm{F} 4 \mathrm{TCNQ}}>0.1 \mathrm{mg} \mathrm{mL}^{-1}$, a doped phase is formed. For both P3HT and P3OT, the cell parameters $a$ and $b$ change simultaneously and progressively as a function of the concentration of incorporated dopants. TEM observations in bright field and HRTEM indicate that the semicrystalline nanomorphology of doped films is almost unaltered after doping. In addition, ED results demonstrate that the order inside the layers of $\pi$-stacked P3HT backbones is preserved upon doping. Therefore, the fact that the intensity of the 002 reflection is not altered upon doping rules out a doping mechanism whereby the $\mathrm{F}_{4}$ TCNQ molecules would be intercalated between polythiophene backbones. ${ }^{[19,21]}$ The present experimental results help support a doping mechanism as illustrated in Figure 2f. In pristine P3HT, side chains and polythiophene backbones are tilted with respect to the $b$-axis and alkyl side chains are not interdigitated. Accordingly, an expansion along the side chain direction and a contraction along the $\pi$-stacking direction support a structural reorganization whereby the $\pi$-stacking of the backbones tends toward a more cofacial arrangement with the side chains oriented perpendicular to the polythiophene backbone. The evolution of the $d_{100}$ period with doping concentration suggests that the tilt of backbones and side chains are controlled by the amount of incorporated $\mathrm{F}_{4} \mathrm{TCNQ}$ in the layers of side chains. For $\mathrm{F}_{4}$ TCNQ-doped P3HT, a saturation of the dopant in the polymer is observed and corresponds to a saturation concentration of approximately one $\mathrm{F}_{4} \mathrm{TCNQ}$ per four hexylthiophene monomers (i.e., one $\mathrm{F}_{4} \mathrm{TCNQ}$ molecule per unit cell). ${ }^{[7]}$ Our results on the influence of doping concentration support the idea of a progressive modification of the unit cell parameters with increasing doping concentration since we did not observe coexistence of doped and undoped crystals of P3HT. However, some threshold concentration is apparently required to trigger the transition to the doped phase, a situation similar to that observed in iodine-doped pentacene. ${ }^{[39]}$

The impact of doping on the family of P3ATs helps better understand the role of the length of alkyl side chains on the $\mathrm{F}_{4}$ TCNQ uptake. The UV-vis-NIR results demonstrate that
$\mathrm{F}_{4} \mathrm{TCNQ}^{-}$anions are oriented by the alkyl side chains in P3HT and P3OT but not in P3BT. This is not surprising because the interlayer spacing along the side chains is only $12.6 \AA$ in pristine P3BT whereas the length of the $\mathrm{F}_{4}$ TCNQ long axis is $\approx 12 \AA$. Accordingly, the layer period of such short side chains is incompatible with, that is, cannot accommodate the long axis dimension of the $\mathrm{F}_{4} \mathrm{TCNQ}$ dopants. This suggests that the long axis of $\mathrm{F}_{4} \mathrm{TCNQ}$ molecules must be tilted to the backbone direction of P3BT. In other words, the ordering of the dopant molecules is determined by the length of alkyl side chains in poly(3-alkylthiophene)s.

Finally, the case of $\mathrm{F}_{4} \mathrm{TCNQ}$ doping of $\mathrm{C}_{12}$-PBTTT is further important to understand the impact of the packing of alkyl side chains on the doping mechanism. The P3ATs investigated herein have layers of non-interdigitated side chains as illustrated in Figure $2 d$. In sharp contrast, in $\mathrm{C}_{12}$-PBTTT the side chains are strongly interdigitated to form a dense lattice. ${ }^{[40]}$ Incorporation of dopant molecules in such interdigitated layers requires major reorganization of the packing of the interdigitated side chains. As observed in our ED patterns, doping of $\mathrm{C}_{12}$-PBTTT with $\mathrm{F}_{4}$ TCNQ results in a significant loss of order in the direction of the polymer chains as witnessed by a substantial intensity loss of the 003 reflection (see Figure 4h). These results indicate that it is more difficult to incorporate $\mathrm{F}_{4} \mathrm{TCNQ}$ molecules into the layers of interdigitated side chains in PBTTT than in the layers of non-interdigitated side chains in P3ATs.

Regarding charge conductivity and its anisotropy, the observed trends with increasing $\mathrm{F}_{4} \mathrm{TCNQ}$ concentration are also interesting. First, the overall anisotropy factors $\sigma_{/ /} / \sigma_{\perp}$ are in the range $5-15$, that is, are similar to the anisotropy of charge mobilities measured in bottom gate bottom contact OFETs of oriented P3HT films. ${ }^{[9]}$ In all cases, the charge conductivity is enhanced along the rubbing direction. However, on a mesoscale, charges must travel through amorphous interlamellar zones that should be marginally doped. Therefore, in order to observe an enhanced charge conductivity on the mesoscale along the rubbing direction (chain direction), the crystallinedoped lamellae of P3HT running perpendicular to the rubbing direction must be somehow interconnected. The $M_{\mathrm{w}}$ of the P3HT sample used in this study is such that the average contour length of the chains exceeds the lamellar period of $23 \mathrm{~nm}$, that is, tie-chains that interconnect successive lamellae are indeed present. However, our previous study on high-T rubbed P3HT has clearly demonstrated that the tie chains crossing the amorphous interlamellar zones have a nonplanar, coiledlike conformation that disrupts $\pi$-conjugation. Moreover, the UV-vis results indicate that doped interlamellar zones are poorly doped by $\mathrm{F}_{4} \mathrm{TCNQ}$. Therefore, doped tie-chains may not be sufficient to explain the enhanced charge conductivity parallel to the rubbing direction. Interconnection between crystalline lamellae may also occur via so-called tie crystallites. A previous HRTEM study on oriented high- $M_{\mathrm{w}}$ P3HT films evidenced tie-crystallites that interconnect crystalline P3HT lamellae. ${ }^{[41]}$ It is most likely that such tie-crystallites also play an important role on the mesoscale charge conductivity in such doped and oriented P3HT films. As for pristine aligned P3HT, the very regular periodic lamellar morphology observed in the oriented P3HT films for $T_{\mathrm{R}}=220{ }^{\circ} \mathrm{C}$ may be detrimental for mesoscale charge conductivities in doped thin films. It is likely 
that the percolation between crystalline domains via doped and highly conducting tie-crystallites is the most efficient way to ensure high charge conductivities along the rubbing direction. ${ }^{[9]}$

Remarkably, the results in Figure $5 \mathrm{c}$ show that the conductivity $\sigma_{\perp}$ is relatively constant and independent of the doping concentration. The conductivity $\sigma_{\perp}$ corresponds to a macroscopic charge transport across multiple crystalline domains of doped P3HT. The films of P3HT rubbed at $180{ }^{\circ} \mathrm{C}$ consist of a mixture of crystals with face-on and edge-on orientations on the substrate but these domains have the same in-plane direction of the chains parallel to the rubbing $R$. Accordingly, in the doped films (where the same proportion of edge-on and faceon crystals are present), charges must cross from face-on to edge-on domains and vice versa. For the face-on domains, $\sigma_{\perp}$ is along the insulating alkyl side chains that correspond to the lowest conductivity. Accordingly, whatever, the doping level, the conductivity perpendicular to the chains, $\sigma_{\perp}$, is always limited by the poor transport of the face-on crystals along the side chain direction. This may explain the relative constancy of $\sigma_{\perp}$ versus doping concentration. Possibly, if the proportion of edge-on crystals could be increased, one could observe a corresponding increase in $\sigma_{\perp}$. This is indeed what was observed for the charge mobility $\mu_{\perp}$ in OFETs for undoped and oriented P3HT when the rubbing temperature was increased. Indeed, for very high rubbing temperatures close to $230{ }^{\circ} \mathrm{C}$, rubbed films consist of a majority of aligned edge-on domains and the corresponding $\mu_{\perp}$ was getting close to $\mu_{/ / \cdot}{ }^{[9]}$

\section{Conclusion}

A simple and efficient method to produce large surfaces of highly oriented, crystalline, and conducting polymer films by combination of high-T rubbing and soft doping from solution is demonstrated. It is versatile and can be applied to a large palette of polymer semiconductors that can be aligned by high-T rubbing (including n-type polymers). ${ }^{[29]}$ Interesting new perspectives are now open to fabricate model systems of conducting polymers with high in-plane orientation and structural perfection that will help understand fundamental aspects and anisotropy of charge transport. This study has already provided compelling evidence for a high level of order and orientation of $\mathrm{F}_{4} \mathrm{TCNQ}^{-}$anions in the matrix of semiconducting polymers such as P3HT. The level of ordering is clearly dependent on the structure of the layers of alkyl side chains that host the dopant molecules. Parameters such as the length of alkyl side chains and their packing into an interdigitated/non-interdigitated sublattice are equally determining for the buildup of ordered doped architectures. Preliminary results indicate that other dopants can likewise be intercalated in the layers of alkyl side chains. Temperature-dependent conductivity and Seebeck coefficient measurements are underway to uncover the impact of orientation on the charge transport mechanism in such highly crystalline conducting polymer films. It remains to evaluate how and to what extent the lamellar semicrystalline structure affects the observed anisotropy of conductivity and thermoelectric properties. In particular, by changing the temperature of rubbing we will be able to control the crystallinity of the rubbed P3HT films and hence evaluate how this crystallinity impacts charge transport in doped conducting and oriented polymer layers.

\section{Experimental Section}

Orientation and Doping of Thin Films: $\mathrm{P} 3 \mathrm{HT}$ was purchased from Merck whereas P3OT and P3BT were purchased from Rieke (the macromolecular parameters are collected in Table S1, Supporting Information). $\mathrm{F}_{4} \mathrm{TCNQ}$ and solvents such as anhydrous chloroform, acetonitrile, and dichlorobenzene were obtained from $\mathrm{TCl}$ or SigmaAldrich and used without purification. Polymer synthesis of $C_{12}$-pBTTT was performed according to ref. [27]. Fractionation by Soxhlet extraction yielded a batch characterized by $M_{\mathrm{w}}=45 \mathrm{kDa}$ and a polydispersity index $(\mathrm{PDI})=1.7$ (see Table S1, Supporting Information).

The preparation of oriented $\mathrm{P} 3 \mathrm{HT}$ films by high-temperature rubbing followed the protocol described in previous publications. ${ }^{[8,9,27,28]}$ Thin polymer films were deposited by spin-coating at $1500 \mathrm{rpm}$ for $60 \mathrm{~s}$ from an $o$-DCB solution $\left(20 \mathrm{mg} \mathrm{mL}^{-1}\right)$ at room temperature, leading to films of thickness $\approx 40 \mathrm{~nm}$. Oriented polymer films were prepared by using a homemade setup consisting of a translating hot plate on which the sample was fixed and a rotating cylinder was covered with a microfiber cloth. The films were rubbed at different rubbing temperatures depending on the polymer $\left(100\right.$ and $220^{\circ} \mathrm{C}$ for $\mathrm{P} 3 \mathrm{HT}, 140^{\circ} \mathrm{C}$ for $\mathrm{P} 3 \mathrm{OT}$, and $125^{\circ} \mathrm{C}$ for $\mathrm{C}_{12}$-PBTTT). For a precise determination of the film conductivity, the film thickness was also measured after rubbing as it generates some material loss. Therefore, the rubbed films were melt-annealed to randomize the in-plane chain direction and the thickness was extracted from the UV-vis absorbance. Concerning P3BT, oriented films were prepared by directional epitaxial crystallization in 1,3,5-trichlorobenzene (TCB) since it was observed to yield a better alignment of the films as compared to high-T rubbing. The method for slow directional epitaxial crystallization has been described in the literature. ${ }^{[27]}$

Doping Protocol: The doping was performed following the method proposed by Jacobs et al. ${ }^{[16]}$ Typically, $250 \mu \mathrm{L}$ of a solution of $\mathrm{F}_{4}$ TCNQ in anhydrous acetonitrile of variable concentration $C_{F 4 T C N Q}$ $\left(0.01-1 \mathrm{mg} \mathrm{mL}^{-1}\right)$ was dropped on the oriented polymer films. It has been verified that acetonitrile is neither dissolving the $\mathrm{P} 3 \mathrm{HT}$ films nor altering the orientation/morphology of the films. The solution was left in contact with the films for $10 \mathrm{~s}$ and the remaining solution was removed from the films by spin-coating at $1500 \mathrm{rpm}$ for $1 \mathrm{~min}$.

Thin Film Characterization: Structural Analysis: TEM: Oriented areas were identified for TEM analysis by optical microscopy (Leica DMR-X microscope). The polymer films were coated with a thin amorphous carbon film and removed from the glass substrate by floating on a diluted aqueous HF solution (10 wt\%) and subsequent recovery on TEM copper grids. TEM was performed in bright field, high-resolution, and diffraction modes using a CM12 Philips microscope equipped with a MVIII (Soft Imaging System) charge coupled device camera Calibration of the reticular distances in the ED patterns was made with an oriented PTFE film. Beam exposure was set to a minimum using the low dose system to avoid dedoping under the electron beam that is observed when the same zone is exposed for a prolonged period of time. Dedoping is clearly manifested in the ED pattern by a change in reticular distances to those of the pristine undoped P3HT films.

Polarized UV-Vis-NIR Absorption: The orientation of the polymer films was probed by UV-vis-NIR absorption (350-2500 nm) using a Cary 5000 spectrometer with polarized incident light and spectral resolution of $1 \mathrm{~nm}$.

Polarized FTIR Spectroscopy: Polarized microinfrared experiments in the middle infrared range $\left(800-4000 \mathrm{~cm}^{-1}\right)$ were carried out in transmittance on a Bruker IFS $66 \mathrm{~V}$ spectrometer coupled with a Hyperion 2000 microscope (Bruker Inc.). A mercury cadmium telluride detector, a $\mathrm{KBr}$ beam splitter, and a blackbody source were used for the experiments. The spectral resolution was $2 \mathrm{~cm}^{-1}$, and 256 scans were added for each spectrum. The samples used for polarized FTIR spectroscopy are prepared on $\mathrm{Si}(100)$ substrates with their native oxide. 
Charge Transport and Seebeck Constant: All devices were fabricated on glass substrates, cleaned by ultrasonication in acetone, hellmanex, deionized water, and isopropanol. The cleaned substrates were dried under nitrogen prior to use. Gold electrical contacts $(25 \mathrm{~nm}$ thick) in a four-point probe geometry $(1 \mathrm{~mm}$ spacing between electrodes, $5 \mathrm{~mm}$ length) were deposited via controlled thermal evaporation through a shadow mask, at an average rate of 4-6 $\AA \mathrm{s}^{-1}$. A first layer of chromium (2.5 $\mathrm{nm}$ thick) was deposited prior the gold to promote a good adhesion on the glass substrates (evaporation rate $0.5-1 \AA \mathrm{s}^{-1}$ ). The contact geometry used for the electrical conductivity and thermopower measurements are presented in Figure S4 (Supporting Information). On the same substrate, two devices were oriented along the rubbing direction (black) and two others in the perpendicular direction (red) which allows to determine the charge transport and thermoelectric anisotropy on a same substrate.

Four-point probe measurements of electrical conductivity were performed using a Keithley 4200-SCS and a Lab Assistant Semiprobe station in a Jacomex glovebox under $\mathrm{N}_{2}$ atmosphere. To derive the resistivity from the sheet resistance $R$ measured on the device geometry given in Figure S4 (Supporting Information), the geometrical correction factor $C$ was first determined such that $R=C \rho / t$ where $t$ is the film thickness. To that aim, a classical four-point probe system was used on a nonoriented doped P3HT film to obtain a reference value of the resistivity $\rho$ given by $R=4.53 / t$. Using this value of the resistivity, the geometrical correction factor was determined for four-line electrode geometry by measuring the sheet resistance on the same sample and obtained $C=1.81$, that is, $R=1.81 \rho / t$

Thermopower measurements were conducted in air on the same devices. The thermopower was measured via the differential temperature method: a temperature gradient was established across the sample either along the rubbing direction or perpendicular to it. The measurements were performed by using a homemade setup made of one heating and one cooling Peltier cells ( $3 \mathrm{~mm}$ gap) (similar to that described by Glaudell et al. ${ }^{[23]}$ ) providing a controllable temperature difference $\Delta T$. Temperatures of the cold and warm sides were measured in noncontact mode using two IR sensors avoiding thus thermal contact issues. The Seebeck tension was measured using a Keithley 2634B sourcemeter and a Semiprobe Lab assistant probe station in ambient conditions. The Seebeck coefficient was calculated from the slope of $V_{\text {therm }}$ versus temperature difference $\Delta T$ for $\Delta T$ varying in a range $\pm 10 \mathrm{~K}$ around $T=23 \pm 2{ }^{\circ} \mathrm{C}$. Typical $V_{\text {therm }}=f(\Delta T)$ is shown in Figure S5 (Supporting Information).

\section{Supporting Information}

Supporting Information is available from the Wiley Online Library or from the author.

\section{Acknowledgements}

L.B. acknowledges financial support from University of Strasbourg through "Investissement d'avenir" (IdEx 2015 "Attractivité") and from the Fédération de Recherche sur les matériaux et nanostructures d'Alsace (FRMNA) via the Région Alsace through contract FRMNA AAP 2015. M.B. acknowledges support from PROCOPE project as well as the University of Strasbourg for the "Investissement d'avenir" (IdEx) Ph.D. grant of V.V. SIMS platform (Montpellier) is also thanked for providing access to IR facility. Technical support from the TEM platform (M. Schmutz and C. Blanck) is gratefully acknowledged. T. Heiser is thanked for providing access to the glove box facility at ICube (Strasbourg). B. Lotz is acknowledged for reading the manuscript and useful comments.

\section{Conflict of Interest}

The authors declare no conflict of interest.

\section{Keywords}

conjugated polymers, conducting polymers, structure and morphology, thermoelectric properties, organic electronics

Received: January 11, 2017

Revised: March 7, 2017

Published online:

[1] A. O. Patil, A. J. Heeger, F. Wudl, Chem. Rev. 1988, 88, 183.

[2] A. Pron, P. Rannou, Prog. Polym. Sci. 2002, 27, 135.

[3] I. F. Perepichka, D. F. Perepichka, Handbook of Thiophene-Based Materials: Applications in Organic Electronics and Photonics, John Wiley \& Sons Ltd, Chichester, UK 2009, pp. i-xxii.

[4] O. Bubnova, Z. U. Khan, A. Malti, S. Braun, M. Fahlman, M. Berggren, X. Crispin, Nat. Mater. 2011, 10, 429.

[5] M. Brinkmann, J. Polym. Sci., Part B: Polym. Phys. 2011, 49, 1218.

[6] R. Noriega, J. Rivnay, K. Vandewal, F. P. V. Koch, N. Stingelin, P. Smith, M. F. Toney, A. Salleo, Nat. Mater. 2013, 12, 1038.

[7] K. Kang, S. Watanabe, K. Broch, A. Sepe, A. Brown, I. Nasrallah, M. Nikolka, Z. Fei, M. Heeney, D. Matsumoto, K. Marumoto, H. Tanaka, S. Kuroda, H. Sirringhaus, Nat. Mater. 2016, 15, 896.

[8] K. Tremel, F. S. U. Fischer, N. Kayunkid, R. DiPietro, A. Kiriy, D. Neher, S. Ludwigs, M. Brinkmann, Adv. Energy Mater. 2014, 4, 1301659.

[9] A. Hamidi-Sakr, L. Biniek, S. Fall, M. Brinkmann, Adv. Funct. Mater. 2016, 26, 408.

[10] X. Xue, G. Chandler, X. Zhang, R. J. Kline, Z. Fei, M. Heeney, P. J. Diemer, O. D. Jurchescu, B. T. O'Connor, ACS Appl. Mater. Interfaces 2015, 7, 26726.

[11] E. Scheler, P. Strohriegl, in Liquid Crystalline Semiconductors: Materials, Properties and Applications (Eds: R. ). Bushby, S. M. Kelly, M. O'Neill), Springer, Dordrecht, Netherlands 2013, p. 197.

[12] a) H. Shirakawa, S. Ikeda, Synth. Met. 1979, 1, 175; b) K. Araya, A. Mukoh, T. Narahara, H. Shirakawa, Synth. Met. 1986, 14, 199; c) N. Coustel, N. Foxonet, J.-L. Ribet, P. Bernier, J. E. Fischer, Macromolecules 1991, 24, 5867.

[13] W. H. Meyer, Synth. Met. 1981, 4, 81.

[14] a) T. Nishizawa, H. K. Lim, K. Tajima, K. Hashimoto, J. Am. Chem. Soc. 2009, 131, 2464; b) T.-R. Chou, S.-H. Chen, Y.-T. Chiang, Y.-T. Lin, C.-Y. Chao, J. Mater. Chem. C 2015, 3, 3760.

[15] a) D. T. Duong, C. Wang, E. Antono, M. F. Toney, A. Salleo, Org. Electron. 2013, 14, 1330; b) C. Wang, D. T. Duong, K. Vandewal, J. Rivnay, A. Salleo, Phys. Rev. B 2015, 91, 085205.

[16] I. E. Jacobs, E. W. Aasen, J. L. Oliveira, T. N. Fonseca, J. D. Roehling, J. Li, G. Zhang, M. P. Augustine, M. Mascal, A. J. Moulé, J. Mater. Chem. C 2016, 4, 3454.

[17] D. T. Scholes, S. A. Hawks, P. Y. Yee, H. Wu, J. R. Lindemuth, S. H. Tolbert, B. J. Schwartz, J. Phys. Chem. Lett. 2015, 6, 4786.

[18] C. Y. Kao, B. Lee, L. S. Wielunski, M. Heeney, I. McCulloch, E. Garfunkel, L. C. Feldman, V. Podzorov, Adv. Funct. Mater. 2009, 19, 1906

[19] J. E. Cochran, M. J. N. Junk, A. M. Glaudell, P. L. Miller, J. S. Cowart, M. F. Toney, C. J. Hawker, B. F. Chmelka, M. L. Chabinyc, Macromolecules 2014, 47, 6836 .

[20] P. Pingel, D. Neher, Phys. Rev. B 2013, 87, 115209.

[21] H. Méndez, G. Heimel, S. Winkler, J. Frisch, A. Opitz, K. Sauer, B. Wegner, M. Oehzelt, C. Röthel, S. Duhm, D. Többens, N. Koch, I. Salzmann, Nat. Commun. 2015, 6, 8560.

[22] R. Kroon, D. A. Mengistie, D. Kiefer, J. Hynynen, J. D. Ryan, L. Yu, C. Muller, Chem. Soc. Rev. 2016, 45, 6147.

[23] A. M. Glaudell, J. E. Cochran, S. N. Patel, M. L. Chabinyc, Adv. Energy Mater. 2015, 5, 1401072 
[24] D. M. DeLongchamp, R. J. Kline, Y. Jung, D. S. Germack, E. K. Lin, A. J. Moad, L. J. Richter, M. F. Toney, M. Heeney, I. McCullough, ACS Nano 2009, 3, 780

[25] B. O'Connor, R. J. Kline, B. R. Conrad, L. J. Richter, D. Gundlach, M. F. Toney, D. M. DeLongchamp, Adv. Funct. Mater. 2011, 21, 3697.

[26] a) M. Brinkmann, J.-C. Wittmann, Adv. Mater. 2006, 18, 860; b) M. Brinkmann, P. Rannou, Macromolecules 2009, 42, 1125.

[27] a) M. Brinkmann, L. Hartmann, L. Biniek, K. Tremel, N. Kayunkid Macromol. Rapid Commun. 2014, 35, 9; b) L. Hartmann, K. Tremel, S. Uttiya, E. Crossland, S. Ludwigs, N. Kayunkid, C. Vergnat, M. Brinkmann, Adv. Funct. Mater. 2011, 21, 4047; c) L. Biniek N. Leclerc, T. Heiser, R. Bechara, M. Brinkmann, Macromolecules 2013, 46, 4014

[28] L. Biniek, S. Pouget, D. Djurado, E. Gonthier, K. Tremel, N. Kayunkid, E. Zaborova, N. Crespo-Monteiro, O. Boyron, N. Leclerc, S. Ludwigs, M. Brinkmann, Macromolecules 2014, 47, 3871.

[29] I. Haller, F. B. Kaufman, J. Am. Chem. Soc. 1976, 98, 1464.

[30] D. A. Dixon, J. C. Calabrese, J. S. Miller, J. Phys. Chem. 1989, 93, 2284.

[31] The absorption coefficient of $\mathrm{F}_{4} \mathrm{TCNQ}^{-}$anions at $793 \mathrm{~nm}$ is equal to $50000 \mathrm{~mol}^{-1} \mathrm{~L} \mathrm{~cm}^{-1}$ which helps determine the concentration of anions in a thin film of thickness $t$. For a thickness $t=30 \mathrm{~nm}$, the absorbance is 0.15 , corresponding to an equivalent concentration of $1.13 \mathrm{~mol} \mathrm{~L}^{-1} \mathrm{~F}_{4} \mathrm{TCNQ}^{-}$. Considering that the film of $\mathrm{P} 3 \mathrm{HT}$ is composed of a crystalline phase with a density close to $1.1 \mathrm{~g} \mathrm{~cm}^{-3}$, this is equivalent to a concentration of $6.63 \mathrm{~mol} \mathrm{~L}^{-1}$ of hexylthiophene monomers (making the assumption that the density of the amorphous phase is close to that of crystalline $\mathrm{P} 3 \mathrm{HT}$ ). Accordingly, the ratio of concentrations of $\mathrm{P} 3 \mathrm{HT}$ and $\mathrm{F}_{4} \mathrm{TCNQ}^{-}$in the film corresponds to $\approx 17 \mathrm{~F}_{4} \mathrm{TCNQ}^{-}$anions for one hundred 3-hexylthiophene monomers.

[32] M. Meneghetti, C. Pecile, J. Chem. Phys. 1986, 84, 4149.

[33] D. Di Nuzzo, C. Fontanesi, R. Jones, S. Allard, I. Dumsch, U. Scherf, E. von Hauff, S. Schumacher, E. Da Como, Nat. Commun. 2015, 6, 6460.

[34] M. Zamadar, S. Asaoka, D. C. Grills, J. R. Miller, Nat. Commun. 2013, 4, 2818

[35] N. Kayunkid, S. Uttiya, M. Brinkmann, Macromolecules 2010, 43, 4961.

[36] A. von Mülhenen, N. Errien, M. Schaer, M.-N. Bussac, L. Zuppiroli, Phys. Rev. B 2007, 75, 115338

[37] K. P. Pernstich, B. Rössner, B. Batlogg, Nat. Mater. 2008, 7, 321.

[38] O. Bubnova, M. Berggren, X. Crispin, J. Am. Chem. Soc. 2012, 134, 16456

[39] M. Brinkmann, V. S. Videva, A. Bieber, J.-J. André, P. Turek, L. Zuppiroli, P. Bugnon, M. Schaer, F. Nuesch, R. Humphry-Baker, J. Phys. Chem. A 2004, 108, 8170.

[40] E. Cho, C. Risko, D. Kim, R. Gysel, N. C. Miller, D. W. Breiby, M. D. McGehee, M. F. Toney, R. J. Kline, J.-L. Brédas, J. Am. Chem. Soc. 2012, 134, 6177.

[41] M. Brinkmann, P. Rannou, Macromolecules 2009, 42, 1125. 